\title{
Patient or Public Education
}

National Cancer Institute

\section{Source}

National Cancer Institute. Patient or Public Education. NCI Thesaurus. Code C19141.

The activities of educating or instructing or teaching that are directed towards a patient or the general public. 